\title{
CORRELATION OF PATIENTS ANXIETY LEVELS, EXPOSURE TO COMPUTER TOMOGRAPHY EXAMINATION AND EXPERIENCE OF CLAUSTROPHOBIA
}

\author{
${ }^{1}$ Hameed, M., ${ }^{* 2}$ Labe, M. R., ${ }^{3}$ Akinjola, A. O., ${ }^{1}$ Anongu, I. T., ${ }^{1}$ Chia, M. D., ${ }^{1}$ Enejo, A. E., \& \\ ${ }^{4}$ Otene, A. S.
}

${ }^{I}$ Department of Radiology, Benue State University Teaching Hospital Makurdi, Nigeria

Email: drhameed2001@yahoo.com

${ }^{2}$ Department of Clinical Psychology, Federal Medical Centre Makurdi, Nigeria

${ }^{3}$ Department of Psychiatry, Benue State University Teaching Hospital Makurdi, Nigeria

${ }^{4}$ Department of Oncology and Palliative Care Federal Medical Centre Makurdi, Nigeria

Corresponding Author E-mail: laberansome@gmail.com

\section{ABSTRACT}

Anxiety is recognized as a potential risk factor for false-positive result derived from radiological image. This study investigated patients' anxiety levels on exposure to computer tomography and experience of claustrophobia. The study adopts a correlation research design. A total of 96 patients made-up of 49 males (50\%) and 47 females (48\%) subjects undergoing CT scan examination at the Radiology Department of Benue State University Teaching Hospital, Makurdi was recruited for this study. Participants responded to STAI (Form-1) a Nigerian re-standardized version and Radomsky's Claustrophobia questionnaire. The results of the analysis shows that; there is a strong positive correlation between patients' levels of anxiety and exposure to computer tomography examination including normal anxiety of $r$ $(96)=.812, \mathrm{p}<.0 .01$ ), mild anxiety level $r(96)=.823, \mathrm{p}<.0 .01)$, moderate anxiety level $r(96)=.746, \mathrm{p}<.0 .01)$, severe anxiety $r(96)=$ $.669, \mathrm{p}<.0 .01$ ), and extremely severe anxiety level, $r(96)=.220, \mathrm{p}<.0 .01)$. However, there is a negative correlation between patients' exposure to computer tomography examination and experience of claustrophobia, $r(96)=-.18, \mathrm{p}<.0 .01$ ). There is also a significant difference between male and female levels of anxiety and experience of claustrophobia during exposure to CT scan examination, with males score $(M=20.4082, S D=2.39721, N=96)$ and females score $(M=21.1489, S D=3.03586), t(94)=-1.330, \mathrm{p}<.05)$ for anxiety, males score $(M=43.0213, S D=12.04609)$, and females score $(M=42.2979, S D=11.89248)$ on exposure to CT scan $t(94)=.293, \mathrm{p}<.05)$ claustrophobia symptoms, males score $(M=15.7083, S D=14.02878)$ females score $(M=13.9149, S D=10.75989), t(94)=.698, \mathrm{p}<.05)$. The study proved that anxiety and claustrophobia is commonly experienced by patients undergoing CT scan examination. Hence, precounselling/education should always be used to prepare as well as mitigate anxiety related reactions in patients prior to CT scan in order to achieve a successful outcome of the procedure.

Keywords: Anxiety levels, Claustrophobia, Computer Tomography, False-positive result, Patients

LICENSE: This work by Open Journals Nigeria is licensed and published under the Creative Commons Attribution License 4.0 International License, which permits unrestricted use, distribution, and reproduction in any medium, provided this article is duly cited.

COPYRIGHT: The Author(s) completely retain the copyright of this published article.

OPEN ACCESS: The Author(s) approves that this article remains permanently online in the open access (OA) mode.

QA: This Article is published in line with "COPE (Committee on Publication Ethics) and PIE (Publication Integrity \& Ethics)". 


\section{INTRODUCTION}

Anxiety is a complex emotional reaction that is disproportionate to a situation that an individual perceived as dangerous under uncertain circumstances (American Psychology Association, 2019). Anxiety can be experienced in relation to specific situations or certain object, and when it is accompanied by a desire to avoid the feared situation or object or when the situation is actually avoided, it is referred to as phobic anxiety state (Olley, 2012). Phobia is a type of anxiety that is characterized by an irresistible fear which has no single aetiological explanation. Individuals obsessed with phobic emotional feelings and reaction are inclined to evade exposure to the feared situation or object. But inevitably, application of medical advanced technology both for diagnosis and treatment is a situation most people cannot avoid if they desire an effective intervention. Invariably, radiological image devices such as Computer Tomography Scan (CT scan) and Magnetic Resonant Imagery are potential stimuli that generates anxiety disorder such as claustrophobia (Grilo et al., 2017). Claustrophobia is a form of anxiety disorder that causes intense fear of enclosed spaces. Some people have claustrophobia symptoms when they are in all types of closed-up areas. Others notice the problem only when they are in certain cramped spaces, like CT scan or MRI (Raman, 2015). As a result, diagnostic procedures that involve an individual confinement can produce anxiety and the patients that are to be placed in a narrow tube exhibits claustrophobic symptom (Raman, 2015). Claustrophobia is different for everyone. Some people with claustrophobia experience mild anxiety when they are in a confined space, whereas others have severe anxiety or panic attack (Fritscher, \& Gans, 2020).

McIsaac, Thordarson, Shafran, Rachman and Poole (1998) stated that the shock of being in a restricted area or confined space can induce claustrophobia. However, McIsaac et al., (1998) further explained that claustrophobia is not a fear of enclosed space itself, but it is the individuals fear of what may occur to him or her in within the space. Consequently, claustrophobia can be defined as a pessimistic expectation of outcomes of being in a confined area (Heyer, Thuring, Lemburg, Kreddig, 2014;7). Claustrophobia in CT and MRI scan is known to be a common problem and a common cause of apprehension amongst patients exposed to examinations with these equipment (Heyer, Thuring, Lemburg, Kreddig, 2014; Fritscher, \& Gans, 2020; Raman, 2015). Anxiety is also associated with what CT scan represents to the patient not only because of the procedure itself but also due to the results expected from the scan (Grilo et al., 2017) which inherently harbors uncertainty (Mishel, 1984). Others are concerned about radiation exposure, administration of contrast agent, communication of results and claustrophobia (Heyer, Thuring, Lemburg, Kreddig, 2014). Studies have shown that patients who have never been exposed to a CT scan showed significant higher anxiety levels than those who had previous examination (Beachy, 2020; Forshaw Carey, Sanson-Fisher, \& Boyes, 2018). People develop anxiety for many reasons such as unpredictability of the diagnosis and claustrophobia. They express increased levels of anxiety and fear before being involved in the medical imaging procedure (Bystritsky, Khalsa, Cameron, Shiffman, 2013).

Some researchers identified the main source of anxiety as the necessity to remain lying in the gantry narrow space during the examination (Dzuida, Zielinski, Baran, \& Krej, 2019). Other specific conditions that increase anxiety levels include female gender, medical condition, and first-time exposure to procedure (Forshaw et al., 2018). Similarly, Beachy (2014) found that females experience greater anxiety levels than men. While Heyer et al., (2015) added that, patients with known malignancies had a significantly high level of anxiety concerning their CT scan results. 
Clearly, evidence from studies conducted in Western countries shows that anxiety and claustrophobia is a disorder that is experienced by many patients in radiological imaging procedure. As it is, radiophobia need to be recognized and properly managed especially with regards to medical radiation decision making (Dauer, Thornton, Hay, Balter, Williamson, German, 2011). Untreated anxiety related distress reaction in radiological imaging do not only has its human toll for the patient, but also considerably taxes departmental resources in terms of appointment cancellations, medication use, prolong recovery, and inability to complete imaging procedures/test well or at all, with adverse impact on both image quality and reimbursement (Schupp, Berbaun, Berbaun, \& Lang, 2005; Auerbach, Martelli, \& Mercuri, 1983; Lang, Ward, \& Laser. 2010; Martin, Lennox, \& Buckley, 2005; Melendez \& McCrank, 1993 cited in Flory, 2011).

Moreover, anxiety can result in a somatic disorder with hyperactivity of the autonomic nervous system which may affect the patient's physical examination, causing problems in the evaluation of radiological images making to non-cooperative patient (Lo Re et al., 2010). Dewey, Schink and Dewey, (2007) observed that because of claustrophobia, panic or other reasons prevent patients from lying still. This could result to losses of revenue for the involved facilities (Lang, Ward, \& Laser 2010). Actually, in Nigeria, patients are becoming regularly exposed to CT scan a type of radiology imaging device which enhance clinical investigation and diagnosis of patients' illnesses.

However, there is a dearth of data on the psychological problems in patients known to interfere with imaging procedure. Consequently, this study seeks to establish patients' levels of anxiety, exposure to CT scan examination and experience of claustrophobia in medical setting to help radiologists to understand and adopt methods to deal with the challenges. Besides, it will also help to expand the reliability of previously established findings from cross-national research focusing on anxiety as underlying psychological problems that often interfered with patients' cooperation to achieve a successful and reliable outcome in radiology imaging procedure of patients.

\section{AIM AND OBJECTIVES}

Anxiety is recognized as a potential risk factor for false-positive result derived from radiological image. Therefore, this study aimed to investigate the probability of Nigerian patients' experience of anxiety and fear (claustrophobia) in situations that they are to undergo a CT scan examination which involves confinement in an enclosed space. The objectives include:

1. to determine the relationship between patient's level of anxiety and exposure to CT scan examination.

2. to establish the relationship between exposure to CT scan and experience of claustrophobia.

3. to determine the significant difference between male and female levels of anxiety and experience of claustrophobia on exposure to CT scan examination.

\section{HYPOTHESES}

The study was designed to test only three hypotheses which were stated in a directional form.

(1) $\mathrm{H}_{\mathrm{A}}$ : There will be a significant correlation between patients' levels of anxiety and exposure to CT scan examination. 
(2) $\mathrm{H}_{\mathrm{A}}$ : There will be a significant relationship between patient's exposure to CT scan and experience of claustrophobia.

(3) $\mathrm{H}_{\mathrm{A}}$ : There will be a significant difference between male and female levels of anxiety and experience of claustrophobia.

\section{METHODOLOGY RESEARCH DESIGN}

A correlation design was adopted for the study with the aim of examining patient's anxiety levels and claustrophobia as potential risk factor for image false-positive result elicited from CT scan. The correlation research design does not require manipulation of variables to establish a cause-and-effect relationship. But only for the purpose of describing the variables and the relationship that naturally occurs between two or more variables and indicates how one variable predict another.

\section{PARTICIPANTS AND SAMPLING TECHNIQUE}

The participants in the study were patients who presented for CT examination in the Radiological Department of Benue State University Teaching Hospital Makurdi. A total of 96 patients were selected through a total population sampling which is a type purposive sampling technique. This was because the participants had specific experience of illnesses that requires an investigation that exposed them to CT scans. The patients comprised of male and females who were recommended to CT scan examination. Their socio-demographic variables were sex, age, ethnicity, educational qualification, religion, marital status. The participants involved in the study met the inclusion criteria of age 18years and above, agreement to participate, ability to read and understand English, and not physically in distress. The participants were genuinely informed to withdraw at any point of responding to the questionnaire for any reasons of physical and emotional distress they experience. Seemingly, not all patients presented for CT scan were eligible for the study because they did not meet the inclusion criteria which exclude defective sight and hearing, age limit, inability to understand and/or read in English.

\section{STUDY INSTRUMENT}

The participants responded to two (2) psychometric tools adopted for data collection. They include the Nigerian revalidated version of STAI-S (FORM X-1) by Spielberger, Gorsuch and Lushene, (1982) and the Claustrophobia Questionnaire (CLQ) by Radomsky, Rachman, Dana, Thordarson, McIsaac and Teachman (2001). The questionnaire has 20 items which requires the respondent to indicate how he or she felt right at the moment of their waiting to undergo CT scan imaging till the end of the session. The instrument had a high reliability coefficient of 0.77 and internal consistency as high as 0.98 (Oladimeji, 2005). The test norms obtained for the Nigerian sample are shown on the graphic table below. 
Table 1: Means and standard deviation of test scores for Nigerian sample

\begin{tabular}{lll}
\hline Sex & STAI (X-1) & STAI (X-2) \\
\hline Male & $\mathrm{X}=45.92$ & $\mathrm{X}=46.67$ \\
$\mathrm{~N}=60$ & $\mathrm{SD}=7.37$ & $\mathrm{SD}=6.65$ \\
& & \\
Female & $\mathrm{X}=39.7$ & $\mathrm{X}=43.53$ \\
$\mathrm{~N}=60$ & $\mathrm{SD}=8.25$ & $\mathrm{SD}=8.83$ \\
\hline
\end{tabular}

Source: Psychological Assessment Techniques in Health Care by Oladimeji B.Y. (2005).

CLQ psychometric properties show a reliable and sensitive measure of claustrophobia and its component fears. The psychometric analysis of CLQ indicates that it has good predictive and discriminant validity as well as good internal consistency and test-retest reliability (Radomsky et al., 2001). The normative data for the CLQ, the SS, and the RS are displayed table 2 .

Table 2: Normative data for the CLQ and its component scales

\begin{tabular}{lcc}
\hline Scale & $\begin{array}{l}\text { Adult M } \\
(\mathrm{SD})\end{array}$ & $\begin{array}{c}\text { Claustrophobia students } \\
\text { M (SD) }\end{array}$ \\
\hline CLQ total & $28.9(19.4)$ & $51.8(16.6)$ \\
SS & $9.1(7.9)$ & $23.8(8.4)$ \\
RS & $19.9(12.8)$ & $27.6(9.6)$ \\
\hline
\end{tabular}

Source: Radomsky et al., (2001) Claustrophobia questionnaire

\section{DATA ANALYSIS}

The spearman rank correlation and independent t-test were used for the analysis of the data collected from the participants. Spearman correlation was used to test the relationship between the variables on the first and second hypothesis respectively. While t-test was used for the third hypothesis which is to determine the significant difference between male and female anxiety level, exposure to CT scan and claustrophobia reaction. Data analysis was done using the statistical packages for social sciences SPSS version21.0 for windows. The results are observed at the significant level of $(\mathrm{p}<0.05)$ level.

\section{RESULTS}

CT scan helps to augment clinical investigation and diagnosis of patients' illnesses. Yet, CT scan examination procedure requires envelopment of a person in a confined space. This often trigger in some people anxiety and claustrophobia which are known to be potential risk factors for false-positive result of radiological image. The purpose 
of the study was to examine patient's levels of anxiety, exposure to CT scan and experience of claustrophobia. The data collected was analyzed and the result obtained was presented in this section of the study.

Table 1: Descriptive summary of Demographic features of participants (n: 96)

\begin{tabular}{lll}
\hline Variables & frequency & percent (\%) \\
\hline Sex & 49 & 50.0 \\
Male & 47 & 48.0 \\
Female & & \\
Age & 34 & $34-7$ \\
$18-35$ & 30 & 30.6 \\
$36-53$ & 22 & 22.4 \\
$54-71$ & 10 & 10.2 \\
$70-60$ & & \\
Patients & 26 & 26.9 \\
Outpatient & 69 & 70.4 \\
Inpatient & & \\
Occupation & 19 & 19.4 \\
Farmers & 25 & 25.5 \\
Public servant & 22 & 22.4 \\
Civil servant & 30 & 30.4 \\
Business persons & & 44.9 \\
Ethnicity & 44 & 27.6 \\
Tiv & 27 & 10.2 \\
Idoma & 10 & 15.3 \\
Igede & 30 & \\
Others &
\end{tabular}

Research data analysis

Table 1 represents the descriptive summary of the demographic characteristics of participants displayed in frequency and percentages. 
Table 2: Correlation matrix of levels of anxiety and exposure to CT scan examination

\begin{tabular}{|c|c|c|c|c|c|c|c|}
\hline & $\mathbf{1}$ & 2 & 3 & 4 & 5 & 6 & 7 \\
\hline NORMAL_ANXIETY Pearson Correlation & 1 & & & & & & \\
\hline \multicolumn{8}{|l|}{ Sig. (2-tailed) } \\
\hline $\mathrm{N}$ & 95 & & & & & & \\
\hline MILD_ANXIETY Pearson Correlation & $.508 * *$ & 1 & & & & & \\
\hline Sig. (2-tailed) & .000 & & & & & & \\
\hline $\mathrm{N}$ & 95 & 96 & & & & & \\
\hline MODERATE_ANXIETY Pearson Correlation & $.428 * *$ & $.496^{* *}$ & 1 & & & & \\
\hline Sig. (2-tailed) & .000 & .000 & & & & & \\
\hline $\mathrm{N}$ & 94 & 95 & 95 & & & & \\
\hline SEVERE_ANXIETY Pearson Correlation & $.426 * *$ & $.382 * *$ & $.554 * *$ & 1 & & & \\
\hline Sig. (2-tailed) & .000 & .000 & .000 & & & & \\
\hline $\mathrm{N}$ & 95 & 96 & 95 & 96 & & & \\
\hline EXTREMELY_SEVERE Pearson Correlation & -.025 & $.469 * *$ & .100 & .024 & 1 & & \\
\hline Sig. (2-tailed) & .812 & .000 & .335 & .814 & & & \\
\hline $\mathrm{N}$ & 95 & 96 & 95 & 96 & 96 & & \\
\hline COMPUTER_TOMO Pearson Correlation & $.812 * *$ & $.823^{* *}$ & $.746^{* *}$ & $.669^{* *}$ & $.220 *$ & 1 & \\
\hline GRAPHY & .000 & .000 & .000 & .000 & .033 & & \\
\hline Sig. (2-tailed) & 94 & 94 & 94 & 94 & 94 & 94 & \\
\hline \multicolumn{8}{|l|}{$\mathrm{N}$} \\
\hline CLAUSTROPHOBIA Pearson Correlation & .132 & -.038 & -.072 & -.105 & -.017 & .018 & 1 \\
\hline SYMPTOMS & .205 & .717 & .488 & .313 & .873 & .861 & \\
\hline Sig. (2-tailed) & 94 & 95 & 94 & 95 & 95 & 93 & 95 \\
\hline $\mathrm{N}$ & & & & & & & \\
\hline
\end{tabular}

** Correlation is significant at the 0.01 level (2-tailed).

Table 2 above shows that there is a strong significant positive association between patients' levels of anxiety and exposure to CT scan examination. Normal anxiety shows a positive relationship of $r(95)=.812, \mathrm{p}<.0 .01$ ), mild anxiety level $r=.823, \mathrm{p}<.0 .01$ ), moderate anxiety level $r=.746, \mathrm{p}<.0 .01$ ), severe anxiety $r=.669, \mathrm{p}<.0 .01$ ), and extremely severe anxiety level $r=.220, \mathrm{p}<.0 .01)$. 
Table 3: Correlation between patient's exposure to CT scan and experience of claustrophobia

$\begin{array}{ll}\text { Exposure to } & \begin{array}{l}\text { Experience of } \\ \text { claustrophobia }\end{array}\end{array}$

Exposure to

CT Scan

Pearson correlation

1

$-0.18$

Sig (2-tailed)

.861

$\mathrm{N}$

94

93

Experience of

Pearson correlation

$-.018$

1

Claustrophobia

Sig (2-tailed)

.861

$\mathrm{N}$

95

**. Correlation is significant at the 0.01 level (2-tailed).

The results of table 3 shows that there is a negative correlation between patients' exposure to CT scan and experience of claustrophobia, $r(94)=-.18, \mathrm{p}<.0 .01)$.

Table 4: Sample description using t-test for equality of means by sex group

\begin{tabular}{|c|c|c|c|c|c|c|}
\hline & \multicolumn{2}{|c|}{ Male } & \multicolumn{2}{|c|}{ Female } & \multirow[b]{2}{*}{ Sig } & \multirow[b]{2}{*}{$\mathbf{t}$} \\
\hline & $\mathbf{M}$ & SD & $\mathbf{M}$ & SD & & \\
\hline Anxiety levels & 20.4082 & 2.39721 & 21.1489 & 3.03586 & .154 & -1.330 \\
\hline Computer tomography & 43.0213 & 12.04609 & 42.2979 & 11.89248 & .302 & .293 \\
\hline Claustrophobic symptoms & 15.7083 & 14.02878 & 13.9149 & 10.75989 & .828 & .698 \\
\hline
\end{tabular}

$\square \square \mathrm{P}<0.05$

Table 3 shows that there is a significant difference between male and female levels of anxiety, exposure to CT scan examination and experience of claustrophobia with male score $(M=20.4082, S D=2.39721)$ and female score $(M=21.1489, S D=3.03586), t(94)=-1.330, p<.05)$ for anxiety, male score $(M=43.0213, S D=12.04609)$ and female score $(M=42.2979, S D=11.89248)$ for exposure to CT $t(94)=.293$, $\mathrm{p}<.05)$ claustrophobia symptoms, male score $(M=15.7083, S D=14.02878)$ female score $(M=13.9149, S D=10.75989), t(94)=.698, \mathrm{p}<.05)$. 


\section{DISCUSSION}

CT scan is an advanced medical technological equipment that helps to augment clinical investigation and diagnosis of patients' illness. The equipment has become available for use in many hospitals in Nigeria for complementally investigations. Its advantages in clinical investigation and diagnosis are enormous. However, CT scan as an examination procedure requires confinement of a person in a cave-like area. Considering the potential capacity of CT scan to induce anxiety, this study aimed to investigate the levels of anxiety and experience of claustrophobia when patients during CT scan examination. Correlation and t-test of independent statistics were used for the analysis of the data. The discussion of the findings is provided in the sequence of the hypotheses tested.

Hypothesis one which was stated to test the relationship between patients' levels of anxiety and exposure to $\mathrm{CT}$ scan examination was accepted. The findings shows a strong significant positive correlation of normal anxiety ( $\mathrm{r}$ $=.812, \mathrm{p}<.0 .01)$, mild anxiety level $(\mathrm{r}=.823, \mathrm{p}<.0 .01)$, moderate anxiety level $(\mathrm{r}=.746, \mathrm{p}<.0 .01)$, severe anxiety $(\mathrm{r}$ $=.669, \mathrm{p}<.0 .01)$, and extremely severe anxiety level $(\mathrm{r}=.220, \mathrm{p}<.0 .01)$ during patient's exposure to CT scan examination. These findings have explicitly backed evidences from previous studies which found that diagnostic procedures that involve an individual confinement can produce anxiety (Raman, 2015). They manifest unusual levels of anxiety and fears even before being involved in a medical imaging procedure (Forshaw, Boyes, Carey et al., n.d.). They frequently show significant greater anxiety levels than those who had previous exposure to CT scan examination (Beachy, 2014; Bystritsky, Khalsa, Cameron, \& Schiffman, 2013). People develop anxiety for many reasons such as unfortunate diagnosis, and claustrophobia due to feeling of uncertainty about unforeseen occurrence.

Hypothesis two which sought to find the relationship between patient's exposure to CT scan and experience of claustrophobia was also accepted. The results revealed a negative correlation between patients' exposure to CT scan and experience of claustrophobia, $(r(96)=-.18, \mathrm{p}<.0 .01)$. This finding too supports the extant literature from studies that claustrophobia in CT scan is a common problem and a common cause of anxiety amongst patients exposed to examinations with this equipment (Heyer et al., 2015; McIsaac et al., 1998; Raman, 2015). For example, McIsaac, Thordarson, Shafran, Rachman and Poole (1998) states that shock of being in a restricted area or an enclosed space can induce the claustrophobia. Although, McIsaac and colleagues explained that claustrophobia is not a fear of enclosed space itself, but it is the fear of what may happen to him or her in that place. This possibly explains the reason for the negative correlation that was found between exposure to CT scan and experience of claustrophobia.

Hypothesis three which aimed to test the difference in male and female levels of anxiety, exposure to CT scan examination and experience of claustrophobia was accepted. The findings derived from the data analysis shows that there is a significant difference between male and female levels of anxiety, exposure to CT scan examination and experience of claustrophobia with male score $(M=20.4082, S D=2.39721)$ and female score $(M=21.1489, S D=$ $3.03586), t(94)=-1.330, \mathrm{p}<.05)$ for anxiety, male score $(M=43.0213, S D=12.04609)$ and female score $(M=42.2979$, $S D=11.89248$ ) for exposure to computer tomography $t(94)=.293, p<.05)$ claustrophobia symptoms, male score of $(M=15.7083, S D=14.02878)$ female score $(M=13.9149, \mathrm{SD}=10.75989), t(94)=.698, p<.05)$. The different emotional reaction between the sex groups levels of anxiety, claustrophobia during exposure to CT scan support other research findings outside Nigeria. For instance, Beachy (2014) and Bystritsky et al., (2013) found that female experience greater anxiety levels than men. Other studies reported also that some people with claustrophobia experience mild 
anxiety when they are in a confined space, whereas others have severe anxiety or panic attack (Fritscher, 2020; NHS, n.d.).

Importantly, the significant differences of anxiety levels and experience of claustrophobia between genders is known to be precipitated by different factors. Dzuida, Zielinski, Baran and Krej (2019) observed that the main source of anxiety is found in the need to remain lying in the narrow gantry space during this examination. Bystritsky et al., (2013) identified some of the specific reasons that increase anxiety levels to include female gender, medical condition, and first-time exposure to an investigation procedure. Heyer et al., (2015) similarly reported that patients with life-threatening illnesses, concern about radiation exposure, administration of contrast agent, communication of results and claustrophobia had a significantly high level of anxiety. However, Grilo, (2017) argued that anxiety is also related to what CT scan represents to the patient not only because of the procedure itself but also due to the results unpredictability expected from the procedure, and inherently harboured uncertainty (Mishel, 1984). In summary, collating from the findings obtained from this current study and the extant literature, it is an indisputable fact that there is a strong correlation between exposure to CT scan and experience of claustrophobia disorder. And men and women react with different levels of anxiety during CT scan examination.

\section{CONCLUSION}

Anxiety disorders are common emotional reaction in the medically ill patients. Unfortunately, anxiety is a psychological problem recognized to be a potential risk factor that influences false-positive result from radiological imaging which blur objective medical examination and diagnosis. In Nigeria, clinical investigation for most illnesses today requires the use of technological devices such as the CT scan to help in identify and ascertain the disease part of the body as well as its nature in order to make an informed decision for an objective and accurate diagnosis and treatment plan. Fundamentally, in contemporary medical practice, advanced medical technologies are successfully aiding positive assessment outcomes and diagnosis for effective treatment requiring pharmacotherapy and surgery. But then, the equipment like the CT scan is known to elicit mild to very severe anxiety and claustrophobia reaction in patients. Evidence from studies have shown that untreated anxiety related distress reaction in radiological imaging not only precipitate unpleasant distress to the patient, but also considerably taxes departmental resources in terms of appointment cancellations, medication use, prolong recovery, and inability to complete imaging procedures/test well or at all, with adverse impact on both image quality and reimbursement. Moreover, anxiety can result in a somatic disorder with hyperactivity of the autonomic nervous system which may affect the patient's physical examination, causing problems in the evaluation of radiological images making to non-cooperative patient. Yet, recommendation of patients for investigations that would expose them to radiological devices has become a regular process in many Nigerian hospitals. In view of this, it is relevant that a systematize clinic interaction approaches with patients should be of great priority to always mitigate patient's anxiety as a preliminary process to their exposure for the procedure.

\section{RECOMMENDATIONS}

1. Pre-scan assessment of patients should always be carried out to identify patients with elevated anxiety levels and fear of exposure to CT scan for possible alleviation. 
2. Education about the pros and cons of being exposed to CT scan should always be provided to patients in order to be well informed for her/him to generate an internal calmness and cooperate to achieve a high-quality imaging result.

3. Health professionals with expertise in the management of emotional distress are required in radiological imaging settings to identify and ease patients' tension and anxiety before CT scan examination.

4. Patients should be subjected to exercise such as deep breathing and muscle relaxation for minutes before undergoing CT scan examination.

\section{FUNDING}

This study was sponsored by the monetary contributions of the authors.

\section{CONFLICT OF INTEREST}

There is no conflict of interest

\section{ACKNOWLEDGEMENT}

The authors thank Fanen Upwa for his assistance and diligence work in the process of imputing and statistical analysis. 


\section{REFERENCES}

American Psychological Association (2019). Anxiety. APA. Retrieved from www.apa.org./topics/anxiety.

Beachy, D. (2014). Patients reveal anxiety over CT imaging. Health imaging. Retrieved from www. Searchgate.net

Bystritsky, A, Khalsa, S.S., Cameron, M.E., \& Shiffman, J. (2013). Current diagnosis and treatment of anxiety disorder. P\&T: A Peer Reviewed Journal for Formulary Management. Retrieved from https:/www.ncbi.nlm.nih.gov/QMC/articles.PMC3628173

Dzuida, L., Zielinkski, P., Baran, P., \& Krej, M. (2015). A study of the relationship between the level of anxiety declared by MRI patients in the STAI questionnaire and respiratory rate acquired by a fibre-optic sensor system. Scientific Reports; 9 (1) DOI: 10.1038/s41598-019.40737. Retrieved from www.researchgate.net/publication

Forshaw, K.L., Carey, M.L., Sanson-Fisher, R.W., \& Boyes, A. (2018). Raised anxiety levels among outpatients to undergo a medical imaging procedure: prevalence and correlates. Journal of American College of Radiology; 15(4): 630-638

Fritscher, L., \& Gans, S. (2020). Claustrophobia: fear of enclosed spaces? Verywellmind. Retrieved from www. Verywellmind.com

Flory, N., and Lang, E.V. (2011). Distress in the radiology waiting room. Retrieved from https//: doi.org/10.11/radiol.111 02211

Grilo, A., Vieira L., Carolino E., Oliveira, C., Pacheco, C., Castro, M., \& Alonso J. (2017). Anxiety in cancer patients during 18 F_FDG PET/CT LOW Dose: A comparison of anxiety levels before and after imaging studies. Nurs. Res. Pract. Retrieved from DOI: 10.1155/2017/30574945 www.ncbi.nim.nih.gov.

Health management (2010). Managing distress, discomfort, and anxiety in imaging. Health management, volume 10 -issue 5. Retrieved from healthmanagement.org

Heyer, C.M., Thuring, J., Lemburg S.P., \& Kreddig, N. (2014). Anxiety of patients undergoing CT imaging: an underestimated problem? Academic Radiology; 22(1); 105-112. Retrieved from DOI: 10.1016/j.acra.2014.07.014, Retrieved from www.Researchgate.net

Lo Re, G., De Luca, R., Muscarneri, P., Dorangricchia, P., Picone, D., Veruccio, G., Pinto, A., Midir, M., Russo, A., Lagalla, R., \& Cicero, G., (2010). Relarionship between anxiety level and radiological investigation among different diagnostic imaging examination in a prospective single-centre study. Radiol Med; 121 (10) p 763-8. Retrieved on the 9th April, 2021 from Doi: 10.1007/5115547-016-0664-z.Epub

Mishel, M.H. (1984). Perceived uncertainty and stress in illness. Research in Nursing Health; (3): 63-171.

McIsaac, H.K., Thordarson, D.S., Shafran, R., Rachman, S., and Poole, G. (1998). Claustrophobia and the magnetic resonance imaging procedure. J Behav Med; Doi: 10.1023/a: 101871016680. PMID: 9642571

Oladimeji, B.Y. (2005). Psychological assessment techniques in health care. ObafemiAwolowo University press. Ile-Ife, Nigeria. 
Olley, B.O. (2012). Abnormal psychology. In Udegbe B, Osinowo S, Balogun S, Sunmola G. (Ed.) Psychology: Perspective in Human Behaviour. Freedom Press; Ibandan-Nigeria

Raman, P. (2015). A study to assess the level of knowledge and anxiety among patients undergoing magnetic resonance imaging at selected hospital, Chennai. Retrieved from www.Repository-tnmgrmu.ac.in.

Randomsky, A.S., Rachman, S., Thordarson, D.S., MCIsaac, H.K., \& Teachman, B.A (2001). The claustrophobia questionnaire. Anxiety Disorders; 15: 287-297. Retrieved from https://pubmed.ncbi,nim,nih,gov

Schupp, J.C., Berbauch, K., Berbauch, M., \& Lang, E.V. (2005). Pain and anxiety during interventional radiologic procedures: effect of patients' state anxiety baseline and modulation by nonpharmacologic analgesia adjuncts. J Vase Interv Radiol; 16(12) p 1585-1592. Retrieved from Google Scholar 